Journal of Mathematics and Statistics 5 (1): 10-14, 2009

ISSN 1549-3644

(C) 2009 Science Publications

\title{
Failure Probability of 2-within-Consecutive-(2, 2)-out-of-(n, m): F System for Special Values of $\mathbf{m}$
}

\author{
E.M.E.L. Sayed \\ Department of Mathematics, Faculty of Science, Ain Shams University, Cairo, Egypt
}

\begin{abstract}
Problem statements: In this research, the researcher aimed to discuses the system failure probability of the model 2-within-consecutive $(2,2)$ out of $(n, m)$ system for special values of $\mathrm{m}$. Approach: The basic idea for evaluating the failure probability was the usage of the number of configuration of $\mathrm{k}(\mathrm{k}=2,3,4)$ parallel columns each contained $\mathrm{n}$ components in a $2 \times 2$-matrix. Results: The equation for the linear k-within $(r, s)$ out of $(n, m)$ system were reached. In this study the failure probability of 2-within-consecutive $(2,2)$ out of $(n, m)$ system for $\mathrm{m}=2,3,4$. Conclusion/Recommendations: In general, it was difficult to evaluate the failure probability in the two-dimensional reliability structures such as the linear k-within (r, s) out of (n, m) system. The researcher established the failure probability and then the reliability of three special cases. It was recommended to generalize the results for any values of $\mathrm{k}, \mathrm{r}, \mathrm{s}$ and $\mathrm{m}$.
\end{abstract}

Key words: System reliability, consecutive-k-out-of-n: F system, 2-dimensional k-withinconsecutive-(r, s)-out-of-(m, n): F system

\section{INTRODUCTION}

The consecutive k-out-of-n: F system has been extensively studied in recent years ${ }^{[1-3]}$. The system is specified by $\mathrm{n}$, the number of components and $\mathrm{k}$, the number of consecutive failed components that lead to system failure. Generalizations of the consecutive-kout-of-n: F system has been reported in a considerable number of papers ${ }^{[4]}$. One of the generalizations is the linear connected-(r, s)-out-of-(n, m): F lattice system. It consists of $\mathrm{mn}$ components arranged in $\mathrm{m}$ rows and $\mathrm{n}$ columns. The system fails whenever there is at least one rectangle of dimension $\mathrm{r} \times \mathrm{s}$ which contains all failed components. Bounds, reliability evaluation and invariant optimal design of the linear connected-(r, s)out-of-(n, m): F lattice system is studied in ${ }^{[4-6]}$. Zuo, Lin and $\mathrm{Wu}^{[7]}$ propose combined k-out-of-n: $\mathrm{F}$, consecutivek-out-of-n: F and linear connected-(r, s)-out-of-(n, m): F lattice system structures and provide recursive formulas for the reliability of the combined system structures. Koutras $^{[8]}$ uses the Markov chain approach for reliability evaluation of Markov chain embeddable systems. He shows that the tool is very useful to a great variety of well-known one-dimensional reliability structures. However, it is very difficult or impossible to apply the idea to two-dimensional reliability structures such as the linear connected-(r, s)-out-of-(n, m): F lattice system and the above-mentioned combined system structures.

A further generalization of the linear connected-(r, s)-out-of-(n, m): F lattice system is the linear k-within $(\mathrm{r}, \mathrm{s})$-out-of-(n, m): F lattice system. It consists of mn components arranged in $\mathrm{m}$ rows and $\mathrm{n}$ columns. The system fails whenever there is at least one cluster of size $\mathrm{r} \times \mathrm{s}$, which contains $\mathrm{k}$ or more failed components. It becomes a linear connected-(r, s)-out-of-(n, m): F lattice system when $\mathrm{k}=\mathrm{rs}$. The linear $\mathrm{k}$-within $(\mathrm{r}, \mathrm{s})$ out-of-(n, m): F lattice system is applied to Thin Film Transistor Liquid Crystal Display failure model. If XGA $(1024 \times 768=$ total 786432 dot $)$ TFT display system fails if and only if more than or equal to 10 dot fail in $10 \times 10$ dot matrix, then the system become to be linear 10-within (10, 10)-out-of (1024, 768): F lattice system $^{[9]}$. Akiba and Yammoto ${ }^{[10]}$ proposed approximate values of reliability of this system. This study gives a simple, direct combinatorial method for determining the system failure probability of the following models:

2-within consecutive-(2, 2)-out-of-(n, 2): F system

2-within consecutive-(2, 2)-out-of-(n, 3): F system

2-within consecutive-(2, 2)-out-of-(n, 4): F system

\section{Notation:}

$\mathrm{p}(\mathrm{n}, \mathrm{k}) \quad$ Probability of system failure, $\mathrm{k}=2,3,4$

$\mathrm{T}_{\mathrm{k}} \quad$ Tables with rows indexed by $\mathrm{r}=0,1,2 \ldots$ and columns indexed by $\mathrm{c}=0,1,2, \ldots, \mathrm{k}=2,3,4$

$\mathrm{p} \quad$ Probability that a component functions

q $\quad 1-\mathrm{p}$

$\alpha(n, k, j)$ Number of configuration of $k(k=2,3,4)$ parallel columns each contains $\mathrm{n}$ components having $\mathrm{j}$ total failures with at least two failed components in a $2 \times 2$-matrix

$\mathrm{C}_{\mathrm{k}}(\mathrm{n}, \mathrm{j}) \quad$ Entry in $\mathrm{T}_{\mathrm{k}} \mathrm{k}=2,3,4$ 


\section{MATERIALS AND METHODS}

States of the system: We denote a functioning and a failed component respectively by $(\circ, \bullet)$. The typical states of the system for $\mathrm{n}=2, \mathrm{k}=2,3,4$ will be shown in Fig. 1.

The states of the system are denoted by $\mathrm{ij}$, where the first digit denotes the number of failed components in the first row and the second digit denotes the number of failed components in the second row

Now, we denote the states in Fig. 1a by 10,20,and 11 respectively and denote the states in Fig. 1 b by 12 , 21 and 11 respectively, for example the state 12 means, the first row contains one failed component and two failed components in the second row.

\section{Assumptions:}

- Each component and the system, is either working or failed

- The failures of the components are mutually sindependent

Theorem: Let $L_{k}(n, j) \quad k=2,3,4$, be the number of configuration of $\mathrm{n} \times \mathrm{k}$-matrix having $\mathrm{j}$ total failures and no two failed components occur in each $(2 \times 2)$-matrix.

Then:

$L_{k}(n, j)=C_{k}(n-j+1, j)$

Proof: First, $\mathrm{k}=2$, for $\mathrm{j}=0,1$, we have by definition and by using $\mathrm{T}_{2}$ :

$$
L_{2}(n, j)=\left(\begin{array}{c}
2 n \\
j
\end{array}\right)
$$

Now, if $2 \leq j \leq 2 n$, the required numbers which end in 0 are enumerated by $\mathrm{L}_{2}(\mathrm{n}-1, \mathrm{j})$. Those end in 01 , are enumerated by $2 \mathrm{~L}_{2}(\mathrm{n}-2, \mathrm{j}-1)$.

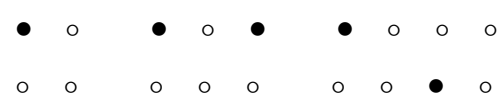

Fig. 1a: Functioning states

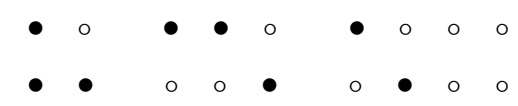

Fig. 2b: Failed states
Then we have:

$$
\mathrm{L}_{2}(\mathrm{n}, \mathrm{j})=\mathrm{L}_{2}(\mathrm{n}-1, \mathrm{j})+2 \mathrm{~L}_{2}(\mathrm{n}-2, \mathrm{j}-1)
$$

The conclusion can be proved by induction: the hypothesis asserts that:

$\mathrm{L}_{2}(\mathrm{n}-1, \mathrm{j})=\mathrm{C}_{2}(\mathrm{n}-\mathrm{j}, \mathrm{j})$

and

$\mathrm{L}_{2}(\mathrm{n}-2, \mathrm{j}-1)=\mathrm{C}_{2}(\mathrm{n}-\mathrm{j}, \mathrm{j}-1)$

However, this implies:

$$
L_{2}(n, j)=C_{2}(n-j, j)+2 C_{2}(n-j, j-1)
$$

and since this is exactly the relation satisfied by the elements of $T_{2}$, this is equivalent to $C_{2}(n-j+1, j)$ :

For $\mathrm{k}=3$

$L_{3}(n, j)=\left(\begin{array}{c}3 n \\ j\end{array}\right), j=0,1$

If $2 \leq j \leq 3 n$, the required numbers which end in 0 are enumerated by $L_{3}(n-1, j)$. Those end in 02 , are enumerated by $L_{3}(n-2, j-2)$. Those end in 01 , are enumerated by $3 L_{3}(n-2, j-1)$. Those end in $011,0111, \ldots$ and $1111 \ldots 11$ are enumerated by $2 \sum_{\substack{i=2 \\ j \geq 2}}^{j} L_{3}(n-i-1, j-i)$ and complete the prove in the same way of the case $\mathrm{k}=2$ :

For $\mathrm{k}=4$

$$
\mathrm{L}_{4}(\mathrm{n}, \mathrm{j})=\left(\begin{array}{c}
4 \mathrm{n} \\
\mathrm{j}
\end{array}\right), \mathrm{j}=0,1
$$

If $2 \leq j \leq 4 n$, the required numbers which end in 0 are enumerated by $\mathrm{L}_{4}(\mathrm{n}-1, \mathrm{j})$. Those which end in 02 are enumerated by $3 L_{4}(n-2, j-2)$. Those end in 01 , are enumerated by $4 \mathrm{~L}_{4}(\mathrm{n}-2, \mathrm{j}-1)$. Those end in 011 , are enumerated by $4 L_{4}(n-2, j-1)$. Those which end by 011 are enumerated by $6 \mathrm{~L}_{4}(\mathrm{n}-3, \mathrm{j}-2)$. Those end in 0111 , are enumerated by $(4+6) \mathrm{L}_{4}(\mathrm{n}-4, \mathrm{j}-3)$. Thus the required number which end in $01,011,0111, \ldots$ and $111 \ldots 11$ are enumerated by $\sum_{i=1}^{j} a_{i} L_{4}(n-i-1, j-i)$ where $a_{i}=a_{i-1}+a_{i-2}$ with $a_{1}=4, a_{2}=6$ and complete the prove in the same way of the case $k=2$. 


\section{RESULTS AND DISCUSION}

With $\alpha(n, k, j)$ as defined in the notation, number of the states which cause system failure, the probability of system failure is:

$$
p(n, k)=\sum_{j=2}^{k n} \alpha(n, k, j) p^{2 n-j} q^{j}
$$

To enumerate the states which cause system failure, we can evaluate, at first, the states at which the system is working and then we subtract this from $\left(\begin{array}{c}\mathrm{kn} \\ \mathrm{j}\end{array}\right), \mathrm{k}=2,3,4$.

A direct method for obtaining $\alpha(n, k, j)$ is by constructing table $T_{k} k=2,3,4$ as follows:

Case 1: When $k=2$, we construct $T_{2}$.

Given $n$, from row 0 through row (n-1) and column 0 through column (n-1) of Table $1 T_{2}$ as follows:

- Entries of row $r=0$ are: A one followed by zeros

- Any entry in row $r>0$ is the sum of the entry just above it and twice the entry immediate left neighbors, i.e.:

$$
C_{2}(n-j+1, j)=C_{2}(n-j, j)+2 C_{2}(n-j, j-1)
$$

The coefficients in $\mathrm{p}(\mathrm{n}, 2)$ are:

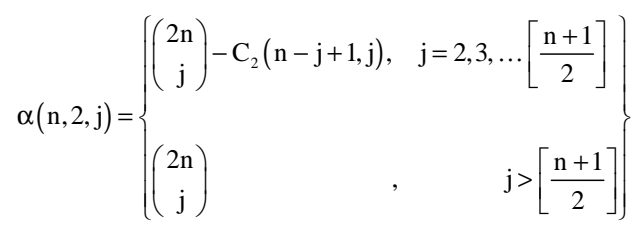

Therefore, $\mathrm{p}(\mathrm{n}, 2)$ is complete determined by (1-3).

Example 1: Suppose that $\mathrm{n}=7$; to find $\mathrm{p}(7,2)$, we construct Table $1 \mathrm{~T}_{2}$ following the previous steps, then using (3), we get

\begin{tabular}{lrrrrrrr}
\multicolumn{7}{l}{ Table 1: The elements in $\mathrm{T}_{2}$} & $\mathrm{n}=7$ \\
\hline $\mathrm{C}$ & 0 & 1 & 2 & 3 & 4 & 5 & 6 \\
\hline $\mathbf{r}$ & & & & & & & \\
0 & 1 & 0 & 0 & 0 & 0 & 0 & 0 \\
1 & 1 & 2 & 0 & 0 & 0 & 0 & 0 \\
2 & 1 & 4 & 4 & 0 & 0 & 0 & 0 \\
3 & 1 & 6 & 12 & 8 & 0 & 0 & 0 \\
4 & 1 & 8 & 24 & 32 & 16 & 0 & 0 \\
5 & 1 & 10 & 40 & 80 & 80 & 32 & 0 \\
6 & 1 & 12 & 60 & 160 & 240 & 192 & 64 \\
\hline
\end{tabular}

$$
\begin{aligned}
& \alpha(7,2,2)=\left(\begin{array}{c}
14 \\
2
\end{array}\right)-C_{2}(6,2)=91-60=31 \\
& \alpha(7,2,3)=\left(\begin{array}{c}
14 \\
3
\end{array}\right)-C_{2}(5,3)=364-80=284 \\
& \alpha(7,2,4)=\left(\begin{array}{c}
14 \\
4
\end{array}\right)-C_{2}(4,4)=1001-16=987 \\
& \alpha(7,2,5)=\left(\begin{array}{c}
14 \\
5
\end{array}\right)=2002 \quad \alpha(7,2,6)=\left(\begin{array}{c}
14 \\
6
\end{array}\right)=3003 \\
& \alpha(7,2,7)=\left(\begin{array}{c}
14 \\
7
\end{array}\right)=3432 \quad \alpha(7,2,8)=\left(\begin{array}{c}
14 \\
8
\end{array}\right)=3003 \\
& \alpha(7,2,9)=\left(\begin{array}{c}
14 \\
9
\end{array}\right)=2002 \quad \alpha(7,2,10)=\left(\begin{array}{c}
14 \\
10
\end{array}\right)=1001 \\
& \alpha(7,2,11)=\left(\begin{array}{c}
14 \\
11
\end{array}\right)=364 \quad \alpha(7,2,12)=\left(\begin{array}{c}
14 \\
12
\end{array}\right)=91 \\
& \alpha(7,2,13)=\left(\begin{array}{c}
14 \\
13
\end{array}\right)=14 \quad \alpha(7,2,14)=\left(\begin{array}{c}
14 \\
14
\end{array}\right)=1
\end{aligned}
$$

Hence:

$$
\begin{aligned}
P(7,2) & =\sum_{j=2}^{14} \alpha(7,2, j) p^{2 n-j} q^{j} \\
& =31 p^{12} q^{2}+284 p^{11} q^{3}+\cdots+14 p q^{13}+q^{14}
\end{aligned}
$$

Case 2: When $\mathrm{k}=3$ we construct $\mathrm{T}_{3}$.

Given n, from row 0 through row (n-1) and column 0 through column (n) of Table $2 \mathrm{~T}_{3}$ as follows:

- Entries of row $r=0$ are consecutive runs of one and zero

- Entries of any row $r>0$ are the sum of the four terms:

- The entry preceding its left neighbor

- The entry just above it

- Triple of the entry immediate left neighbor to the entry of 2)

- Twice of the entries immediate left neighbor to the entry of 3)

i.e.:

$$
\begin{aligned}
& C_{3}(n-j+1, j)=C_{3}(N-J+1, J-2)+ \\
& C_{3}(n-j, j)+3 C_{3}(n-j, j-1)+\sum_{\substack{i=2 \\
j \geq 2}}^{j} C_{3}(n-j, j-i)
\end{aligned}
$$


J. Math. \& Stat., 5 (1): 10-14, 2009

Table 2: The elements in $T_{3} n=4$

\begin{tabular}{lllrrr}
\hline $\mathbf{C}$ & 0 & 1 & 2 & 3 & \multicolumn{1}{c}{} \\
\hline $\mathbf{r}$ & & & & & \\
0 & 1 & 0 & 1 & 0 & 1 \\
1 & 1 & 3 & 4 & 8 & 9 \\
2 & 1 & 6 & 16 & 34 & 65 \\
3 & 1 & 9 & 37 & 105 & 250 \\
\hline
\end{tabular}

The coefficients in $\mathrm{p}(\mathrm{n}, 3)$ are:

$$
\alpha(n, 3, j)=\left\{\begin{array}{rr}
\left(\begin{array}{c}
3 n \\
j
\end{array}\right)-C_{3}(n-j+1, j), & j=2,3, \ldots 2\left[\frac{n+1}{2}\right] \\
\left(\begin{array}{c}
3 n \\
j
\end{array}\right) & , \quad j>2\left[\frac{n+1}{2}\right]
\end{array}\right\}
$$

Example 2: Suppose that $\mathrm{n}=4$; to find $\mathrm{p}(4,3)$, we construct Table $2 \mathrm{~T}_{3}$ following the previous steps, then using (6), we get:

$$
\begin{aligned}
& \alpha(4,3,2)=\left(\begin{array}{c}
12 \\
2
\end{array}\right)-C_{3}(3,2)=66-37=29 \\
& \alpha(4,3,3)=\left(\begin{array}{c}
12 \\
3
\end{array}\right)-C_{3}(2,3)=220-34=186 \\
& \alpha(4,3,4)=\left(\begin{array}{c}
12 \\
4
\end{array}\right)-C_{3}(1,4)=495-9=486 \\
& \alpha(4,3,5)=\left(\begin{array}{c}
12 \\
5
\end{array}\right)=792 \quad \alpha(4,3,6)=\left(\begin{array}{c}
12 \\
6
\end{array}\right)=924 \\
& \alpha(4,3,7)=\left(\begin{array}{c}
12 \\
7
\end{array}\right)=792 \quad \alpha(4,3,8)=\left(\begin{array}{c}
12 \\
8
\end{array}\right)=495 \\
& \alpha(4,3,9)=\left(\begin{array}{c}
12 \\
9
\end{array}\right)=220 \quad \alpha(4,3,10)=\left(\begin{array}{l}
12 \\
10
\end{array}\right)=66 \\
& \alpha(4,3,11)=\left(\begin{array}{l}
12 \\
11
\end{array}\right)=12 \quad \alpha(4,3,12)=\left(\begin{array}{l}
12 \\
12
\end{array}\right)=1
\end{aligned}
$$

Hence:

$$
\begin{aligned}
P(4,3) & =\sum_{j=2}^{12} \alpha(4,3, j) p^{3 n-j} q^{j} \\
& =29 p^{10} q^{2}+18 p^{9} q^{3}+\cdots+12 p q^{11}+q^{12}
\end{aligned}
$$

Case 3: When $k=4$ we construct $T_{4}$.

\begin{tabular}{lccrrr}
\multicolumn{6}{l}{ Table 3: The elements in $\mathrm{T}_{4} \mathrm{n}=4$} \\
\hline $\mathrm{C}$ & 0 & 1 & 2 & 3 & 4 \\
\hline $\mathbf{r}$ & 1 & 0 & 3 & 0 & 9 \\
0 & 1 & 4 & 12 & 24 & 79 \\
1 & 1 & 8 & 37 & 130 & 414 \\
2 & 1 & 12 & 78 & 372 & 1486 \\
\hline
\end{tabular}

Given $\mathrm{n}$, from row 0 through row $\mathrm{n}$ and column 0 through column $\mathrm{n}$ of table $\mathrm{T}_{4}$ as follows:

- Entries of row $r=0$ are consecutive runs of $3^{r}$ and zero for $r=0,1,2 \ldots$

- Entries of any row $r>0$ are the sum of three terms:

- Triple of the entry preceding its left neighbor

- The entry just above it.

- $a_{i}$ multiple of entry immediate left neighbors to the entry 2) where $a_{i}=a_{i-1}+a_{i-2}$ with $a_{1}=4$, $\mathrm{a}_{2}=6$

i.e.:

$C_{4}(n-j+1, j)=3 C_{4}(n-j+1, j-2)$

$+C_{4}(n-j, j)+\sum_{i=1}^{j} a_{i} C_{4}(n-j, j-i)$

where, $\mathrm{a}_{\mathrm{i}}=\mathrm{a}_{\mathrm{i}-1}+\mathrm{a}_{\mathrm{i}-2}$ with $\mathrm{a}_{1}=4, \mathrm{a}_{2}=6$.

The coefficient in $\mathrm{p}(\mathrm{n}, 4)$ are:

$$
\alpha(n, 4, j)=\left\{\begin{array}{lr}
\left(\begin{array}{c}
4 n \\
j
\end{array}\right)-C_{4}(n-j+1, j), & j=2,3, \ldots 2\left[\frac{n+1}{2}\right] \\
\left(\begin{array}{c}
4 n \\
j
\end{array}\right), & j>2\left[\frac{n+1}{2}\right]
\end{array}\right\}
$$

Example 3: Suppose that $\mathrm{n}=4$; to find $\mathrm{P}(4,4)$, we construct Table $3 \mathrm{~T}_{4}$ following the previous steps, then using (9), we get:

$$
\begin{aligned}
& \alpha(4,4,2)=\left(\begin{array}{c}
16 \\
2
\end{array}\right)-C_{4}(3,2)=120-78=42 \\
& \alpha(4,4,3)=\left(\begin{array}{c}
16 \\
3
\end{array}\right)-C_{4}(2,3)=560-120=440 \\
& \alpha(4,4,4)=\left(\begin{array}{c}
16 \\
4
\end{array}\right)-C_{4}(1,4)=1820-47=1773 \\
& \alpha(4,4,5)=\left(\begin{array}{c}
16 \\
5
\end{array}\right)=4368 \quad \alpha(4,4,6)=\left(\begin{array}{c}
16 \\
6
\end{array}\right)=8008 \\
& \alpha(4,4,7)=\left(\begin{array}{c}
16 \\
7
\end{array}\right)=11440 \quad \alpha(4,4,8)=\left(\begin{array}{c}
16 \\
8
\end{array}\right)=12870
\end{aligned}
$$




$$
\begin{array}{ll}
\alpha(4,4,9)=\left(\begin{array}{c}
16 \\
9
\end{array}\right)=11440 & \alpha(4,4,10)=\left(\begin{array}{l}
16 \\
10
\end{array}\right)=8008 \\
\alpha(4,4,11)=\left(\begin{array}{l}
16 \\
11
\end{array}\right)=4368 & \alpha(4,4,12)=\left(\begin{array}{l}
16 \\
12
\end{array}\right)=1820 \\
\alpha(4,4,13)=\left(\begin{array}{l}
16 \\
13
\end{array}\right)=560 & \alpha(4,4,14)=\left(\begin{array}{l}
16 \\
14
\end{array}\right)=120 \\
\alpha(4,4,15)=\left(\begin{array}{l}
16 \\
15
\end{array}\right)=16 & \alpha(4,4,16)=\left(\begin{array}{l}
16 \\
16
\end{array}\right)=1
\end{array}
$$

Hence:

$$
\begin{aligned}
P(4,4) & =\sum_{j=2}^{16} \alpha(4,4, j) p^{4 n-j} q^{j} \\
& =42 p^{14} q^{2}+440 p^{13} q^{3}+\cdots+16 p q^{15}+q^{16}
\end{aligned}
$$

\section{CONCLUSION}

In this study, we study the failure probability of the model 2-Within consecutive-(2, 2)-out-of-(n, m): F system, for $\mathrm{m}=2,3,4$. We make exact simple formula of the failure probability in these cases. We construct Table 1-3 from which we get $\alpha(\mathrm{n}, \mathrm{j}, \mathrm{k})$ when $\mathrm{m}=2,3$, 4.

\section{ACKNOWLEDGEMENT}

I'm pleased to acknowledge many helpful comments made by the editors and referees.

\section{REFERENCES}

1. Zhang, Y.L. and Y. Lam, 1998. Reliability of consecutive-k-out-of-n: G repairable system. Int. J. Syst. Sci., 29: 1375-1379. DOI: 10.1080/00207729808929623
2. Kossow, A. and W. Preuss, 1989. Reliability of consecutive-k-out-of-n: F systems with nonidentical component reliabilities. IEEE Trans. Reliabil., 38: 229-233. DOI: 10.1109/24.31112

3. Papastavridis, S.G., 1989 Lifetime distribution of circular consecutive-k-out-of-n: F systems with exchangeable lifetimes. IEEE Trans. Reliabil., 38: 460-461. DOI: 10.1109/24.46464

4. Cui, L. and M. Xie, 2005. On a generalized k-outof-n system and its reliability. Int. J. Syst. Sci., 36: 267-274. DOI: 10.1080/00207720500062470

5. Salvia, A.A. and W.C. Lasher, 1990. Twodimensional consecutive-k-out-of-n: $F$ models. IEEE Trans. Reliabil., 39: 382-385. DOI: 10.1109/24.103023

6. Koutras, M.V., G.K. Papadopoulos and S.G. Papastavridis, 1993. Reliability and design of 2-dimensional consecutive-k-out-of-n: F systems. IEEE Trans. Reliabil., 42: 658-661. DOI: 10.1109/24.273602

7. Zuo, M.J., D. Lin and Y. Wu, 2000. Reliability evaluation of combined k-out-of-n: F, consecutivek-out-of-n: $F$ and linear connected-(r, s)-out-of-(m, n): F system structures. IEEE Trans. Reliabil., R-49, pp.99-104. DOI: $10.1109 / 24.855542$

8. Koutras, M.V., 1996. On a markov chain approach for the study of reliability structures. J. Applied Probabil., 33: 357-367. http://cat.inist.fr/?aModele=afficheN\&cpsidt=3173872

9. Akiba and Yamamoto, 2005. Evaluating methods for the reliability of a large 2-dimensional rectangular k-within-consecutive-(r, s)-out-of-(m, n): F system. Naval Res. Logist., 52: 243-252. DOI: 10.1002/nav.20067

10. Papastavridis, S.G. and M.V. Koutras, 1993. Bounds for reliability of consecutive k-within-mout-of-n: F systems. IEEE Trans. Reliabil., 42: 156-160. DOI: 10.1109/24.210288 